\title{
Mission possible: Targeting trailers to movie audiences
}

Received: 5th January, 2005

\section{Thomas Kim Hixson}

is an assistant professor who teaches advertising at the University of Winsconsin-Whitewater. He received his Ph.D in journalism from Southern Illinois University. Prior to his career in academe, he was an advertising copywriter and a television promotion manager. His research interests include entertainment and sport marketing and promotion, uses and gratifications, and advertising effects.

\begin{abstract}
The effectiveness of using genre preference segmentation and behaviour segmentation to target movie trailers is explored. Participants from two samples watched trailers and were surveyed. They reported their movie genre preferences and the expected entertainment value of the advertised movies. The data indicate that moviegoers with similar genre preferences have similar reactions to trailers, making effective preference and behaviour segmenting possible for use as a method to target movie trailers.
\end{abstract}

\section{INTRODUCTION}

Advertisers have used various methods of segmenting audiences to designate target audiences. Demographics, psychographics, behaviour, attitudes, needs and benefits received have been used alone or in combination as a method of segmentation. ${ }^{1}$ Movie marketers have successfully utilised demographics and psychographics as a means of targeting audiences for movie ads placed on television, but have been less successful targeting audiences with these methods for movie trailers presentations. ${ }^{2}$ Wedel notes that 'segments should be homogeneous, sizable, responsive to marketing effort and stable over time. ${ }^{3}$ Because of the nature of movie trailers as an advertising medium, demographic segments are not stable enough from movie to movie to use as an effective targeting method. For movie marketers to learn the demographic make-up of the audience that each movie attracts takes too much time to accomplish and leaves too little time to place the targeted trailer in front of that targeted audience.
Segments built on genre preference, however, do meet Wedel's requirements. Still, putting trailers in cinemas in front of the right audience is difficult and has become a 'political morass'. ${ }^{4}$ Studios, distributors and exhibitors each want trailers presented to benefit their marketing efforts and want no competitors' trailers shown before their film. Aside from these conflicts, segmenting moviegoers in cinemas by demographics to target trailers has proven difficult to accomplish effectively, given the various likes and dislikes of entertainment fare. Furthermore, some movie marketers believe trailers should be pitched to the widest possible audience and desire to see their trailers placed in front of movies attracting large audiences. ${ }^{5}$

Can moviegoers be segmented effectively for targeting movie trailers to them in cinemas? Some movie marketers have begun to segment audiences by their genre preferences to target trailers in cinemas. They are creating multiple trailers for multiple audiences. ${ }^{6}$ Are these 
movie marketers on the right track to improved segmenting? In this study, preference and behaviour segmentation will be examined as methods used to segment. Little research has been done on movie genres in marketing, yet it is known that genre preference often guides the viewing behaviour of moviegoers. ${ }^{7}$ Therefore, effective targeting of movie advertising, particularly movie trailers, seems likely, with this method, but is unproven.

People have various expectations about what they will see when they go to cinemas to watch movies. They bring with them genre preferences that may have an effect on the movie choice. ${ }^{8}$ Similarly, in television programme choice, programme preference type is seen as one cause of preferring one programme to another. ${ }^{9,10}$ Because a moviegoer must be more active in attending a movie than is a television viewer in watching a programme, however, it may be assumed that moviegoers are more demanding in having their expectations gratified than are television viewers. ${ }^{11}$ Watching a movie's trailer may play a role in a moviegoer's demand for gratification. Exposure to a movie trailer has been found to produce increased expectations of the amount of particular content in a movie. $^{12}$

A combination of genre preference and intended gratifications would be a useful way of identifying the affective/emotional component in gratifications sought from a movie. ${ }^{13}$ Two researchers have suggested that genre preference could possibly determine the level of satisfaction that a moviegoer derives from viewing a movie. ${ }^{14}$ As such, it may be extrapolated that genre preference plays a role in the movie attendance decision.

Identifying market segments through the use of preference data has some advantages over benefit segmentation. This market segment identification method is 'logical, straightforward and parsimonious'. ${ }^{15}$ This study of moviegoer segmentation makes use of both preference and behaviour segmentation because of the nature of the product and the advertising medium (trailers) exposure. Preference segmentation in this study is closely related to expected-benefit segmentation. A moviegoer chooses a particular movie based on their genre preference because they expect that that preference will fulfil an entertainment desire. Therefore, the moviegoer receives the benefit of having their desire fulfilled.

Scholarly research into the marketing and promotion of motion pictures, which has never been abundant, has been even more limited since the cessation in 1991 of the annual publication of Current Research in Film: Audiences, Economics, and Law. ${ }^{16}$ Researchers have lamented the lack of published material on movie promotion and noted many interesting questions that need to be explored, including: how does movie promotion affect different audiences? And, is movie marketing affected by genre? ${ }^{17}$ This study tries to fill some of the void of movie marketing research.

\section{LITERATURE REVIEW}

\section{Previous studies in segmenting audiences}

Segmenting audiences to target advertising messages requires the advertiser to identify audience member characteristics that may be used to divide the mass audience into smaller, more manageable segments. Segmentation takes a heterogeneous market and sees it as several smaller homogeneous markets 'in response to differing preferences, attributable to the desires of customers 
for more precise satisfactions of their varying wants'. ${ }^{18}$

Benefit segmentation, ${ }^{19}$ as mentioned, is closely related to preference segmentation in this study. Benefit segmentation has been considered as the 'most strategically meaningful' method of segmentation, ${ }^{20}$ although it is not used as often as demographic and geographical segmentation. Another segmentation method, less often used, is behavioural segmentation. This method is often based on selecting prospects that have exhibited behaviour that the marketer wants. ${ }^{21}$

Industry-specific methods of segmentation have been developed based on preference or behaviour - for example, the tourism industry segments on trip-related variables. ${ }^{22}$ The hospitality industry market can be segmented by a combination of type of lodging preferred and sought. ${ }^{23}$ Non-profit organisations can segment based on the contributors' motivations for association with the organisation. ${ }^{24}$

Television programming segmentation methods, however, are most closely related to segmenting the market for a motion picture. In television programming, demographic and socioeconomic data serve as 'surrogate indicators of interests and needs'. ${ }^{25}$ Why use them for segmenting, however, when more direct measurements of viewing behaviour are available? Television viewers can be segmented based on their programme preferences, as there is a close relationship between preference segmentation and behaviour segmentation. ${ }^{26}$ In most cases, it can be assumed, programme preference would guide the behaviour of watching particular programmes. For motion picture marketers, preference and viewing behaviour segmentation might be accomplished through the use of moviegoers' genre preferences. This method of segmentation could be based on the genre of movie that the moviegoer has come to the cinema to see. It may be assumed that moviegoers have a favourable attitude or preference toward the genre of the movie that they are viewing. When the measures utilised to segment are closely related to actual buying behaviour (as they are in this study), more successful segmenting may take place. ${ }^{27}$

Some marketers use a 'marketing engineering' approach to making strategic marketing decisions in areas such as media decisions, targeting and segmentation. ${ }^{28}$ Up-to-date, detailed customer data are necessary for this approach, but this requires consumers to provide detailed information about their identities and preferences before a personal, profitable relationship can be built. ${ }^{29}$ The television advertising industry can provide its advertisers, including movie marketers, such data about its medium. Movie marketers recognise the usefulness of this information and make use of it. In 2003, more than $\$ 1.6 \mathrm{bn}$ was spent on network television advertising as an average of $\$ 8.1 \mathrm{~m}$ was spent on 194 Motion Picture Association of America (MPAA) released movies. ${ }^{30}$ Television provides control over the placement of the movie's advert with specific target audiences found watching specific programmes. ${ }^{31}$

Movie marketers have great difficulty using this 'marketing engineering' approach with trailers, as segmenting the movie audience for advertising success can be very difficult. Demographic variables, except for age and marital status, have been found to be insignificant predictors of cinema attendance. ${ }^{32}$ Movies in cinemas have a very short product life, making the opening week essential to the success of most movies. An important predictor of opening week revenues and a movie's marketability is the advertising support provided for the film. ${ }^{33}$ Because movies 
are pulled from the cinema in only a few weeks, this situation makes gathering and analysing detailed data on the customers of each movie, and therefore, the target audience, almost impossible to complete in an appropriate time period. Research is done on trailers as movie marketers often use focus groups to learn what scenes will most appeal to audiences. A problem with targeting trailers is the marketer's desire to place trailers before 'blockbuster' movies that will attract a large audience. This sometimes results in advertising clutter, with as many as six to eight trailers playing before a movie. ${ }^{34}$

Movie consumers can use a variety of sources to get information to help them select a movie to attend. Some sources, such as advertising, are controlled by movie marketers, but other sources, such as word-of-mouth are not under their control. There has been disagreement among scholars, marketers and industry pundits, however, about which sources are most effective in influencing a moviegoer's decision about which movie to attend. Since movie advertisers have begun using the internet, they have been re-evaluating the value of traditional media. ${ }^{35}$ Some movie marketers believe that controlled media (advertising) sources are becoming more important due to the necessity of a strong opening weekend for a movie ${ }^{36}$ as opposed to letting word-of-mouth 'buzz' spread. With as many as 25 movies advertised on television weekly, a crowded, cluttered media environment has developed there for movie advertisers. ${ }^{37}$

\section{Movie genre preferences}

While a moviegoer may attend any movie to satisfy a need such as the need to pass time, why does a moviegoer choose to attend, for example, Shrek 2 instead of Harry Potter and the Goblet of Fire? The selection of a particular movie to attend, it may be assumed, is made on the basis of the entertainment value that one expects the movie to provide. Movie marketers could use this expected entertainment value as a tool in efforts to promote a particular movie more effectively.

Knowledge of a movie's plot or genre has been salient in most research concerning the reasons why people attend a specific movie or movies in general. ${ }^{38-41}$ Because trailers provide moviegoers with a sample of the movie (a form of direct experience), prospective moviegoers can learn about plot and genre best by watching a trailer. Movie trailers can be targeted to moviegoers based on their behaviour of attending movies at a specific cinema. ${ }^{42}$

When people decide to attend an entertainment event, such as a movie, their motivations for attending the event can arise from a variety of needs. ${ }^{43}$ The motivation for attending movies is, therefore, the expected gratification of a need. Although motivations for attending movies have been identified, the motivations for attending a particular movie have not been specified. Pundits believe that moviegoers rely heavily on filmmaker-produced genre labels and trailers when making a movie selection. ${ }^{44}$ As it may be assumed that genre preference plays a role in meeting these moviegoer motivations or entertainment needs, these needs, grounded in genre preference, could be used to segment movie audiences. As more movies are made for niche audiences, genre preference targeting of trailers is becoming more imperative for successful movie marketing. ${ }^{45}$

\section{Movie trailers}

Movie trailers were used as a stimulus in this study. Trailers are clips of film that are shown prior to the featured movie, 
to advertise other movies. Trailers, along with television, are the most effective media used by movie advertisers to communicate to their target audiences. ${ }^{46}$ Movie trailers enable the prospective moviegoer to view portions of the advertised movie; therefore, this advertising medium provides a sample of the product that the consumer might purchase. This sample enables the moviegoer to decide whether the movie is a genre they prefer. For many moviegoers, trailers are an integral part of the cinema-going experience. Trailers even have their own awards, much like the Oscars, called the Golden Trailer Awards.

Trailers have evolved from being assembled from discarded film footage to being created by the studios and now by independent trailer producers. A current trend by studios is to 'Frankenstein' trailers made by trailer producers. 'Frankensteining' occurs when movie marketers hire several trailer production companies to make trailers for a movie. Although these multiple trailer production companies can be used to create trailers to appeal to particular demographic and genre preference groups, ${ }^{47}$ the marketers take several trailers then cut various parts that have tested well and edit them together into a new trailer for a 'Frankenstein' effect. Even though those parts may have tested well, this new creation offers little chance of being effectively targeted to a specific group.

\section{Hypotheses}

$\mathrm{H}_{1}$ A moviegoer's genre preferences will predict the entertainment value the moviegoer attaches to the advertised movie after being exposed to the trailer.

In order for meaningful segmenting to take place, some identifiable characteristics must be available. Segmenting moviegoers by genre preferences is possible if $\mathrm{H}_{1}$ is supported. This segmentation enables movie marketers to target trailers based on the behaviour of the moviegoer who has shown that he or she will watch a particular genre of movie at one particular cinema.

$\mathrm{H}_{2}$ The stronger the genre preference and the more a person perceives the movie (based on the trailer) to be of that same genre, the greater the likelihood to attend (or not attend) that movie.

This hypothesis further tests the utility of using genre preference as a segmentation method and a targeting tool. By being able to perceive the movie as having elements of several genres, moviegoers can be targeted based on their genre preference. Movie marketers may do this by producing trailers that appeal to a particular genre. ${ }^{48}$

\section{METHODOLOGY}

Two studies were conducted, one using a classroom sample and the other a field sample. The classroom sample provided internal validity by enabling the researchers to make certain that the participants were actually exposed to the stimuli (trailers). The field sample, taken in a commercial movie cinema, provided external validity by enabling the researchers to have participants exposed to the stimuli (trailers) in the natural setting of a movie cinema. The researchers were not able to have each sample exposed to the same trailers; therefore, no comparison of the samples was made.

\section{Participants}

The classroom sample consisted of 158 students at a midwestern university. 
Fifty-five per cent of the participants were female. The participants' ethnic backgrounds consisted of 89.9 per cent white, 3.8 per cent African-American and 1.9 per cent Asian or Pacific

Islander. The age range was 18-24 years. The median age was 20 years. Median family income was in the $\$ 50,001-60,000$ range.

The field sample consisted of 152 moviegoers who took part in the study as they were leaving a commercial movie cinema auditorium. This sample was completed in six days during a two-week period at a suburban motion picture multiplex in a metropolitan area in the Midwest. Participants were selected using a systematic method. ${ }^{49}$ Fifty-nine per cent of the participants were female. The participants' ethnic background consisted of 85.5 per cent white, 2.0 per cent Hispanic, 2.6 per cent Asian or Pacific Islander, and 9.9 per cent other or refused to answer. The age range was $18-72$ years. The median age was in the 38-47 range. Only 18.4 per cent of the participants did not have a four-year college degree. Thirty-five per cent had graduate degrees. Median household income was in the $\$ 40,001-\$ 50,000$ range.

Only those moviegoers exiting from a particular auditorium where the stimuli trailers were shown were eligible for inclusion in the sample.

\section{Variables}

\section{Stimuli}

Trailers used as stimuli in the study advertised movies that had not yet been released: Mask of Zorro and Jackie Brown (classroom sample) and Les Misérables and Lost in Space (field sample).

\section{Predictor variables}

Movie genre preference was the type of movie, based on its content, that the moviegoer likes to attend. Although most movies have content elements that could 'fit' into different movie genres, the type of movie is based on the content's predominant theme. This $a$ priori categorisation of viewing preferences is consistent with Kim's study $^{50}$ of segmenting television audiences.

To measure movie genre preference, participants were asked the degree to which they liked to watch each of six movie genres. A moviegoer's genre preferences are not mutually exclusive. A Likert-type scale was used to measure the strength of the preference of each genre. This method is consistent with that used in another study of segmentation. ${ }^{51}$

Movie genre perception was the movie genre that the participant perceives the movie advertised in the trailer to be. Participants were asked to what degree they thought the movie in the trailer was a particular movie genre. A movie can be categorised as being of several genres; therefore, participants were asked to respond to six items, with each item concerning a different genre. A Likert-type scale was used to measure the strength of the perception of each genre.

\section{Criterion variables}

Attendance likelihood was the degree to which a moviegoer was likely to go to a cinema to see the movie advertised in the trailer.

Expectations of entertainment value (used to construct the expected entertainment value scale) were the expected gratifications that were perceived to result from attending and watching the movie advertised in the trailer. A Likert-type scale was used to measure the concept of expectations of entertainment value. This scale was used for participants to describe the degree to 
which they have a particular expected entertainment gratification after seeing the trailer.

\section{Expected entertainment value scale construction}

A list of 13 items was produced for the formulation of an index. These items represent the concept of expectations of entertainment value or gratifications expected from the movie by the participants after being exposed to each trailer. ${ }^{52}$ A Likert-type scale was used to measure the intensity of each of the gratifications expected. This list of gratifications expected was formulated after perusing similar lists. ${ }^{53}$

An index was then constructed using data from selected expected entertainment gratifications. In accordance with standard factor analysis procedures, ${ }^{54}$ a correlation analysis was used to discover how strongly the items for each trailer related to one another. Then, an exploratory factor analysis was applied using the principal component analysis on the data for each trailer. The purpose was to identify factors that underlie the variables and to reduce the data by including as many variables as possible to see what loaded on the relevant component. To further test the accuracy of the selected items, a standardised alpha reliability analysis was performed.

\section{RESULTS}

\section{Determining the expected entertainment value scale}

The principal component factor analysis loaded six of the 13 items on the entertainment component. For this study, the entertainment component was the only component of interest, and the only one used in constructing the index. To enhance reliability, because the data resulted from four different stimuli, stringent criteria for inclusion on a component were established. To load on a component, a variable had a loading of $\geq 0.5$ and a difference $\geq 0.2$ on any other component. For the variables included in the entertainment value scale, one (warm-hearted) loaded on the component for all four trailers. Four (excite, happy, carefree and enlighten) loaded on the component for three trailers. One (amuse) loaded on the component for one trailer, but was included in the scale because it was a match conceptually with the other selected items. This conceptual match was confirmed through the reliability analysis described below ${ }^{55}$ (Tables 1 and 2).

The six items selected were found to be strongly reliable measures of the expected entertainment value for all four trailers. The scores on these six items for each participant were summed to create the expected entertainment value scale. The standardised alpha reliability analysis of the six selected items ranged from 0.75 to 0.81 in the classroom study and from 0.67 to 0.85 in the field study. For Mask of Zorro and Jackie Brown, the reliability coefficient was a standardised item alpha of 0.82 and 0.83 , respectively. For Les Misérables and Lost in Space, the reliability coefficient was a standardised item alpha of 0.76 and 0.83 , respectively.

All of the participants' expected entertainment value scale scores for a particular movie were summed. The mean of this sum represents the expected entertainment value for that movie (Table 3).

The usefulness and appropriateness of the expected entertainment value scale as a tool to segment movie audiences was tested by examining the correlation between the two criterion variables: expected entertainment value and 
Table 1: Factor loadings of expectations to produce expected entertainment value scale - Classroom study

\begin{tabular}{llrlrrr} 
& \multicolumn{2}{l}{$\begin{array}{l}\text { Mask of Zorro } \\
\text { component }\end{array}$} & \multicolumn{4}{c}{$\begin{array}{l}\text { Jackie Brown } \\
\text { component }\end{array}$} \\
Expectation & $\mathbf{1}$ & $\mathbf{2}$ & \multicolumn{1}{c}{$\mathbf{3}$} & $\mathbf{1}$ & $\mathbf{2}$ & $\mathbf{3}$ \\
\hline Excite & $0.67^{*}$ & 0.47 & 0.01 & $0.69^{*}$ & 0.47 & -0.26 \\
Happy & $0.77^{*}$ & 0.34 & -0.06 & $0.71^{*}$ & 0.36 & -0.06 \\
Warm-hearted & $0.75^{*}$ & -0.06 & -0.01 & $0.70^{*}$ & -0.18 & 0.34 \\
Enlightened & $0.71^{*}$ & -0.33 & -0.12 & $0.74^{*}$ & -0.12 & 0.41 \\
Carefree & $0.65^{*}$ & 0.28 & -0.21 & $0.73^{\star}$ & 0.16 & -0.04 \\
Sexual arousal & $0.64^{*}$ & -0.18 & -0.05 & $0.65^{*}$ & -0.10 & -0.15 \\
Educate & $0.58^{*}$ & -0.40 & 0.33 & 0.64 & 0.00 & 0.50 \\
Amuse & 0.55 & 0.42 & 0.29 & 0.55 & 0.52 & -0.25 \\
Bore & 0.53 & 0.63 & -0.05 & 0.29 & 0.68 & -0.21 \\
Anger & -0.31 & 0.66 & -0.18 & -0.34 & 0.65 & 0.20 \\
Embarrass & -0.27 & 0.41 & 0.55 & -0.27 & 0.64 & 0.42 \\
Afraid & -0.46 & 0.37 & 0.44 & -0.47 & 0.48 & 0.38 \\
Sadden & -0.52 & 0.38 & -0.53 & -0.48 & 0.58 & -0.10 \\
\hline
\end{tabular}

Note: percentage of variance explained (Mask of Zorro $=59$ per cent; Jackie Brown $=62$ per cent) Principal component analysis $p<0.01$

*Loads on entertainment value component $(\geq 0.5$, difference $\geq 0.2)$

Table 2: Factor loadings of expectations to produce expected entertainment value scale - Field study

\begin{tabular}{|c|c|c|c|c|c|c|c|}
\hline \multirow[b]{2}{*}{ Expectation } & \multicolumn{3}{|c|}{$\begin{array}{l}\text { Lost in Space } \\
\text { component }\end{array}$} & \multicolumn{2}{|c|}{$\begin{array}{l}\text { Les Misérables } \\
\text { component }\end{array}$} & \multirow[b]{2}{*}{3} & \multirow[b]{2}{*}{4} \\
\hline & 1 & 2 & 3 & 1 & 2 & & \\
\hline Happy & $0.85^{\star}$ & 0.16 & -0.20 & 0.63 & 0.53 & -0.08 & -0.02 \\
\hline Excite & $0.77^{*}$ & 0.28 & -0.13 & 0.62 & 0.01 & 0.47 & 0.29 \\
\hline Carefree & $0.73^{*}$ & 0.06 & -0.20 & 0.49 & 0.47 & -0.50 & -0.05 \\
\hline Amuse & $0.71^{*}$ & 0.23 & -0.17 & 0.46 & 0.49 & -0.16 & 0.18 \\
\hline Warm-hearted & $0.67^{*}$ & 0.01 & -0.12 & $0.67^{\star}$ & 0.23 & -0.05 & -0.30 \\
\hline Bore & $0.66^{*}$ & 0.27 & 0.02 & 0.40 & -0.01 & 0.54 & 0.53 \\
\hline Sexual arousal & $0.53^{*}$ & -0.38 & 0.23 & 0.33 & -0.16 & -0.52 & 0.42 \\
\hline Enlightened & 0.51 & -0.25 & 0.66 & $0.69^{\star}$ & -0.10 & -0.05 & -0.44 \\
\hline Educate & 0.49 & -0.29 & 0.41 & $0.63^{*}$ & -0.33 & 0.15 & -0.20 \\
\hline Anger & 0.07 & 0.74 & 0.05 & -0.43 & 0.63 & 0.11 & 0.15 \\
\hline Embarrass & -0.03 & 0.73 & 0.30 & 0.01 & 0.24 & 0.67 & 0.01 \\
\hline Sadden & -0.29 & 0.58 & 0.45 & -0.38 & 0.50 & -0.21 & 0.06 \\
\hline Afraid & -0.55 & 0.26 & -0.16 & -0.39 & 0.43 & 0.44 & -0.35 \\
\hline
\end{tabular}

Note: percentage of variance explained (Lost in Space $=57$ per cent; Les Misérables $=60$ per cent) Principal component analysis $p<0.01$

*Loads on entertainment value component $(\geq 0.5$, difference $\geq 0.2)$

Table 3: Expected entertainment value

\begin{tabular}{llll}
\hline Movie & $\boldsymbol{n}$ & M & SD \\
\hline Mask of Zorro & 158 & 21.51 & 6.34 \\
Jackie Brown & 156 & 21.91 & 6.74 \\
Les Misérables & 149 & 21.45 & 6.51 \\
Lost in Space & 129 & 15.43 & 7.27 \\
\hline
\end{tabular}

Note: $M=$ mean of the expected entertainment value

attendance likelihood. The mean of the sum of the participants' attendance likelihood scores for a particular movie represents the attendance likelihood score for that movie (Table 4). Table 5 shows a strong positive correlation for these variables for both movies' trailer, seen by the classroom sample. For the trailers seen by the field sample, Table 5 shows a moderate positive correlation for Les 
Table 4: Attendance likelihood

\begin{tabular}{llll}
\hline Movie & $\boldsymbol{n}$ & $\mathbf{M}^{\boldsymbol{*}}$ & SD \\
\hline Mask of Zorro & 158 & 4.22 & 1.73 \\
Jackie Brown & 156 & 4.88 & 1.94 \\
Les Misérables & 149 & 5.32 & 1.73 \\
Lost in Space & 129 & 2.95 & 2.00 \\
\hline
\end{tabular}

*1 = 'not very likely', 7 = 'very likely'. M=mean of attendance likelihood score of the movie

Misérables and a strong positive correlation for these variables for Lost in Space.

\section{Hypothesis 1}

To determine a method to segment movie audiences for the purpose of targeting trailers, the study explored whether the expected entertainment value could be predicted by a moviegoer's genre preferences. In choosing a movie to attend, a moviegoer's behaviour is based on a preference for a movie genre. ${ }^{56}$ Movie marketers can then assume an audience's genre preference by the movie those moviegoers are watching. By this method, segmentation and effective targeting based on behaviour may be accomplished.

To test, the backward solution method was used in the regression analysis performed on the data. For Mask of Zorro, as Table 6 indicates, three of the six possible genre preferences were included in the regression model of the expected entertainment value $(F$ $\left.(4,153)=2.6, R^{2}=0.06, p=0.04\right)$. However, only action/adventure was significant as a single variable and made the strongest contribution to the prediction. The hypothesis was supported.

For Jackie Brown, as Table 7 indicates, five of the genre preferences were included in the regression model of the expected entertainment value $(F$ $\left.(5,155)=2.38, R^{2}=0.07, p=0.04\right)$.
Although the regression model was significant, no individual genre preference was significant. Note that three of these five genre preferences have negative regression coefficients and $t$-values,

Table 5: Pearson correlation coefficients of expected entertainment value and attendance likelihood

\begin{tabular}{lll}
\hline Movie trailer & $\boldsymbol{n}$ & $\boldsymbol{r}$ \\
\hline Mask of Zorro & 158 & $0.570^{\star \star}$ \\
Jackie Brown & 156 & $0.668^{\star \star}$ \\
Les Misérables & 149 & $0.426^{\star \star}$ \\
Lost in Space & 129 & $0.689^{\star \star}$ \\
\hline${ }^{* *} p<0.01$ & &
\end{tabular}

Table 6: Genre preference predictors of expected entertainment value for Mask of Zorro

\begin{tabular}{llll}
\hline Genre preference & $\mathbf{M}$ & $\boldsymbol{b}$ & $\boldsymbol{t}$ \\
\hline Action/adventure & 5.27 & 0.22 & $2.59^{\star \star}$ \\
Drama & 5.16 & 0.06 & 0.72 \\
Comedy & 6.11 & 0.06 & 0.69 \\
\hline
\end{tabular}

$n=158, p=0.04$

${ }^{* *} p<0.01$. $M=$ mean of the degree to which participants prefer to watch movies of that genre: $1=$ not very much, $7=$ very much. $b$ (beta)=standardised coefficient of the genre to the expected entertainment value

Table 7: Genre preference predictors of expected entertainment value for Jackie Brown

\begin{tabular}{llrr}
\hline Genre preference & $\mathbf{M}$ & \multicolumn{1}{l}{$\boldsymbol{b}$} & \multicolumn{1}{l}{$\boldsymbol{t}$} \\
\hline Action/adventure & 5.27 & 0.12 & 1.35 \\
Comedy & 6.12 & 0.10 & 1.21 \\
Horror/science fiction & 4.26 & -0.05 & -0.54 \\
Romance & 4.60 & -0.08 & -0.79 \\
Family/children & 3.28 & -0.17 & -1.80 \\
\hline
\end{tabular}

$n=156, p=0.04$. M=mean of the degree to which participants prefer to watch movies of that genre: $1=$ not very much, $7=$ very much. $b$ (beta)=standardised coefficient of the genre to the expected entertainment value 
Table 8: Genre preference predictors of expected entertainment value for Les Misérables

\begin{tabular}{llrl}
\hline Genre preference & M & \multicolumn{1}{l}{$\boldsymbol{b}$} & \multicolumn{1}{l}{$\boldsymbol{t}$} \\
\hline Drama & 5.68 & 0.22 & $2.75^{\star \star}$ \\
Family/children & 3.74 & 0.04 & 0.64 \\
Action/adventure & 4.25 & -0.07 & 0.43 \\
Horror/science fiction & 2.91 & 0.11 & 0.23 \\
\hline
\end{tabular}

$n=148, p=0.05$

${ }^{* *} \mathrm{p}<0.01$. M=mean of the degree to which participants prefer to watch movies of that genre: $1=$ not very much, $7=$ very much. $b$ (beta)=standardised coefficient of the genre to the expected entertainment value

indicating that participants who favoured these genres did not expect to be entertained by the movie. The hypothesis was supported, but the genre preferences were weak predictors in this case.

For Les Misérables, as Table 8 indicates, four of the genre preferences were included in the regression model of the expected entertainment value $(F$ $\left.(4,147)=2.49, R^{2} 2=0.07, p=0.05\right)$. One genre preference, action/adventure, had a negative effect on the regression model. Only drama was significant as a single variable. Therefore, it made the strongest contribution to the prediction. The hypothesis was supported.

For Lost in Space, as seen in Table 9, five genres were included in the significant regression model of the expected entertainment value $(F$ $\left.(6,125)=8.55, R^{2}=0.30, p<0.001\right)$. However, only two genre preferences (drama, horror/science fiction) were significant as single variables. These two genre preferences made the strongest contributions to the prediction. Drama, along with comedy and romance, had a negative regression coefficient and a negative effect on the regression model, but horror/science fiction had a strong positive effect. The hypothesis was supported.

The $\mathrm{H}_{1}$ results indicate that genre preference can predict a moviegoer's entertainment value positively or negatively for a movie after he or she
Table 9: Genre preference predictors of expected entertainment value for Lost in Space

\begin{tabular}{llrl}
\hline Genre preference & M & \multicolumn{1}{l}{$\boldsymbol{b}$} & \multicolumn{1}{l}{$\boldsymbol{t}$} \\
\hline Horror/science fiction & 2.97 & 0.47 & $5.55^{\star * *}$ \\
Action/adventure & 4.25 & 0.05 & 0.57 \\
Comedy & 5.87 & -0.03 & -0.40 \\
Romance & 5.36 & -0.12 & -1.40 \\
Drama & 5.68 & -0.23 & $-2.87^{\star *}$ \\
\hline
\end{tabular}

$n=126, p=0.000$

${ }^{* *} p<0.01,{ }^{* \star *} p<0.001 . M=$ mean of the degree to which participants prefer to watch movies of that genre: $1=$ not very much, $7=$ very much. $b$ (beta)= standardised coefficient of the genre to the expected entertainment value

sees a trailer. The regression models indicate that genres can work in concert to lead to a prediction. These predictors are weak to moderate in strength.

Therefore, moviegoers' behaviour based on their genre preferences could be an effective segmentation device.

\section{Hypothesis 2}

To further test, a strong preference for a particular genre, coupled with a strong perception that the movie advertised in the trailer was of that same genre, were found to be predictors of movie attendance likelihood in some cases. With the classroom sample, when using the trailer for Mask of Zorro as the stimulus, significant $(p<0.05)$ predictors were found in three of the six possible genres $(n=158)$. The strongest predictor of movie attendance likelihood was found when a strong preference for the action/adventure genre was coupled with the perception that Mask of Zorro was an action/adventure movie (Table 10). The hypothesis was supported.

When using the trailer for Jackie Brown as the stimulus, significant $(p<0.05)$ predictors were found in five of the six genres. The strongest predictor of movie attendance likelihood was found when a strong preference for the action/adventure genre was coupled with 
Table 10: Genre (preference and perception) predictors of movie likelihood of attendance (classroom study)

\begin{tabular}{llllllc}
\hline & \multicolumn{2}{c}{ Mask of Zorro } & \multicolumn{3}{c}{ Jackie Brown } \\
Genre preference & df & $\boldsymbol{R}^{\mathbf{2}}$ & $\mathbf{F}$ & df & $\boldsymbol{R}^{\mathbf{2}}$ & $\mathbf{F}$ \\
\hline Action/adventure & 157 & 0.08 & $6.93^{\star \star \star}$ & 155 & 0.14 & $12.15^{\star \star \star}$ \\
Romance & 157 & 0.04 & $3.17^{\star}$ & 155 & 0.10 & $8.43^{\star \star \star}$ \\
Family/children & 157 & 0.05 & $3.89^{\star}$ & 155 & 0.04 & $3.05^{\star}$ \\
Drama & 157 & 0.03 & 2.62 & 155 & 0.09 & $7.15^{\star \star}$ \\
Comedy & 157 & 0.03 & 2.52 & 155 & 0.07 & $5.14^{\star \star}$ \\
Horror/science fiction & 157 & 0.00 & 0.09 & 155 & 0.02 & 1.58 \\
\hline
\end{tabular}

$n=158$ (Mask of Zorro), $n=156$ (Jackie Brown)

${ }^{*} p<0.05,{ }^{* *} p<0.001,{ }^{* \star *} p<0.001$

Table 11: Genre (preference and perception) predictors of movie likelihood of attendance (field study)

\begin{tabular}{llllllc}
\hline & \multicolumn{2}{l}{ Les Misérables } & \multicolumn{3}{c}{ Lost in Space } \\
Genre preference & df & $\boldsymbol{R}^{\mathbf{2}}$ & $\mathbf{F}$ & df & $\boldsymbol{R}^{\mathbf{2}}$ & $\mathbf{F}$ \\
\hline Drama & 151 & 0.17 & $14.91^{\star \star \star}$ & 129 & 0.06 & $4.26^{\star}$ \\
Romance & 147 & 0.06 & $4.24^{*}$ & 126 & 0.04 & 2.52 \\
Family/Children & 151 & 0.02 & 1.72 & 129 & 0.01 & 0.65 \\
Horror/science fiction & 150 & 0.02 & 1.71 & 128 & 0.21 & $16.69^{\star \star \star}$ \\
Comedy & 151 & 0.00 & 0.26 & 129 & 0.03 & 1.85 \\
Action/adventure & 151 & 0.00 & 0.31 & 129 & 0.09 & $6.25^{\star \star}$ \\
\hline
\end{tabular}

$n=152$ (Les Misérables), $n=130$ (Lost in Space)

${ }^{\star} p<0.05,{ }^{\star *} p<0.01,{ }^{\star \star \star} p<0.001$

the perception that Jackie Brown was an action/adventure movie (Table 10). The hypothesis was supported. The genre preferences and perceptions that were found to be significant predictors are weak to near-moderate predictors. The proportion of variance of the dependent variable accounted for by the

independent variables ranged from 0.04 to 0.18 .

With the field sample, a strong preference for a particular genre, coupled with a strong perception that the movie advertised in the trailer was of that genre, was found to be a predictor of movie attendance likelihood in some cases. With Les Misérables as the stimulus, significant $(p<0.05)$ predictors were found in two of the six possible genres $(n=152)$. The strongest predictor of movie attendance likelihood was found when a strong preference for drama was coupled with the perception that Les Misérables was a drama (Table 11). The hypothesis was supported.
With Lost in Space as the stimulus, significant $(p<0.05)$ predictors were found in three of the genres $(n=130)$. The strongest predictor of movie attendance likelihood was found when a strong preference for horror/science fiction was coupled with the perception that Lost in Space was a horror/science fiction movie (Table 11). The hypothesis was supported. The genre preferences and perceptions that were found to be significant predictors are weak to moderate predictors. The proportion of variance of the dependent variable accounted for by the independent variables ranged from 0.06 to 0.29 .

The results strengthen the notion that preference segmentation can be used effectively for targeting trailers. Moviegoers with different genre preferences can perceive a movie (based on its trailer) to be of the particular genre for which they have a strong preference. This situation can predict movie attendance likelihood. 


\section{DISCUSSION}

As the data here indicate, preference and behavioural segmentation can be used effectively to target movie trailers to movie audiences. The moviegoing public can be divided into homogeneous markets based on their preferences of genres when they select a movie to attend. Movie advertisers can then target trailers to these segments. Behavioural segmentation is also possible. When the moviegoer's preference of genre is coupled with the perception that the trailer's movie is of that genre, the moviegoers' attendance behaviour to that movie can be predicted. These findings show the usefulness of segmenting by genre preference and of targeting trailers to moviegoers with specific genre preferences, as exhibited by their behaviour of attending a particular movie.

\section{Genre preferences as predictors of entertainment value}

The data demonstrate that genre preference plays a role in predicting the expected entertainment value of a movie based on what the moviegoer feels about the movie from its trailer. Trailers stimulate the moviegoer to have an expectation of what entertainment gratifications will be satisfied. The expected entertainment value scale represents these entertainment gratifications numerically.

The data gathered in the field survey show a preference for Les Misérables, a drama, as opposed to Lost in Space, a horror/science fiction genre movie, in expected entertainment value. Attendance likelihood was low for Lost in Space, but was higher than the expected entertainment value score might indicate. The correlation of attendance likelihood and expected entertainment value was much lower than for the other three movies advertised. This seems to indicate that many moviegoers would attend Les Misérables, not because they might be entertained by it, but perhaps because they would be expected to see a film based on a literary work. Note that 82 per cent of this audience have a four-year degree and 35 per cent have graduate degrees. This was an interesting, serendipitous finding. Motivations such as this one and others probably play a role in the movie selection process, and may account for the moderate to low proportions of variance $\left(R^{2}\right)$ found here. These moderate to low proportions are comparable with those previously found with variables affecting movie selection. ${ }^{57}$

A negative effect was found with some genre preferences on three of the advertised movies. This shows the robustness of using genre preferences as a segmentation method. Not only will a preference for a genre work to attract viewers to a movie, but also a preference for a genre can lead viewers to expect little entertainment value in a movie if the trailer does not address the viewers' desire to see a particular genre. Careful selection of genre preferences to appeal to when producing trailers is needed to advertise movies effectively through the trailer medium. A trailer can dissuade as well as persuade a moviegoer to attend a movie, making preference segmentation even more essential to a movie's box office success.

The findings in this study also suggest that trailers can be targeted to moviegoers based on their preference of genre by the movie they are attending. This situation could make targeting of trailers easy to accomplish. ${ }^{58}$ Although, overall, the survey audiences ranked Lost in Space lowest in expected entertainment value, those who preferred the horror/science fiction genre and categorised the movie as being of that genre had a high level of attendance likelihood for the movie. 


\section{Genre preference and perception as a predictor of movie attendance likelihood}

Moviegoers with similar preferences and perceptions are likely to have similar behaviour, as gauged by their likelihood of attending the advertised movie. For the most part, these variables are moderate to strong predictors. This information is important because of the accessibility that these predictors provide for targeting trailers. For example, a moviegoer who has a high preference for comedy attends a movie and is exposed to a trailer. This moviegoer perceives the movie advertised in the trailer to be a comedy. These two conditions then lead the behaviour of the moviegoer to a greater likelihood of attending that movie. While these premises may seem intuitive, movie marketers have only recently began producing different trailers for different audiences, and not all movies are marketed using this strategic method. Still, the idea of placing the trailers in front of the appropriate audience is not always accomplished. The problem of competing studios, distributors and cinema chains still exists and sometimes prevents the strategically effective placement of trailers in front of the correct audience.

However, this should not deter studios from producing trailers that can be targeted toward a particular segment of the moviegoing public. As indicated here, genre preference and the behaviour of moviegoers can be used for effective targeting of trailers, a very powerful yet relatively inexpensive form of advertising movies.

The results show that moviegoers with different genre preferences can perceive a movie (based on its trailer) to be the genre for which they have a strong preference. For the Jackie Brown trailer, five of the six possible genre preferences and perceptions were found to be significant predictors of movie attendance likelihood. Apparently, moviegoers can perceive what they want to perceive about the content in a movie trailer if given the appropriate visual and verbal cues. This situation makes targeting trailers by genre preference viable.

These findings strengthen the suggestion that genre preferences have an effect on movie choice. In this study, the added variable of perceiving the movie to be of the preferred genre enhances the likelihood of choosing the movie. The data also indicate that movie trailers can be targeted effectively toward those moviegoers who have indicated a genre preference by the movie they are attending; therefore, moviegoers can have trailers targeted to them based on their viewing behaviour.

Although there could be concern about generalising the results because items in the questionnaires were reactions to specific stimuli, it should be remembered that this study sought to explore the possibilities of segmenting audiences based on preferences and behaviour. The results support these possibilities.

Finally, note that segmenting and targeting moviegoers by genre preference and behaviour are the most convenient and accessible methods for the motion picture industry. Detailed demographic and psychographic data, while helpful, are costly, difficult to obtain in a timely manner and unnecessary with genre preference and behaviour segmenting so conveniently available. Other entertainment venues such as television, cinema concerts, and sporting events might also make effective use of these segmentation methods.

\section{References and notes}

1 Wyner, G. A. (1992) 'Segmentation design', Marketing Research, Vol. 4, No. 4, pp. 38-42.

2 DeSilva, I. (1998) 'Consumer selection of motion pictures', in Litman, B. R. (ed.) 'The motion picture mega-industry', Allyn \& Bacon, Needham Heights, MA. 
3 Wedel, M. (2001) 'Is segmentation history?' $A M A$ Marketing Research, Vol. 13, No. 4; pp. 27-29.

4 Hayes, D. (2002) 'Trailer trove', Variety, 7th March, pp. A1, A6,

5 Hayes, D. and Bing, J. (2004) 'Tyranny of the trailer', Variety, 23rd February, pp. 1, 53.

6 Graser, M. (2003) 'Frankenstein effect. Big six hitching hopes to trailers', Variety, 9th July, pp. A1, A8.

7 Desia, K. K. and Basuroy, S. (2005) 'Interactive influence of genre familiarity, star power, and critics' reviews in the cultural goods industry: The case of motion pictures', Psychology \& Marketing, Vol. 22, No. 3, pp. 203-223.

8 Austin, B. A. and Gordon, T. F. (1987) 'Movie genres: Toward a conceptualized model and standard definitions', in: Austin, B. A. (ed.) 'Current research in film: Audiences, economics, and law', 3. Ablex Publishing, Norwood, NJ, pp. 13-33.

$9 \mathrm{Kim}, \mathrm{C}$. (2002) 'Identifying viewer segments for television programs', Journal of Advertising Research, Vol. 42, No. 1, pp. 51-66.

10 Webster, J. G. and Wakshlag, J. J. (1983) 'A theory of television programme choice', Communication Research, Vol. 10, No. 4, pp. 430-446.

11 Shapiro, M. E. and Biggers, T. (1987) 'Emotion-eliciting qualities in the motion picture viewing situation and audience evaluations', in: Austin, B. A. (ed.) 'Current research in film: Audiences, economics, and law', 3. Ablex Publishing, Norwood, NJ, pp. 1-11.

12 Eastman, S. T., Bradbury D. E. and Nemes R. S (1985) 'Influences of previews on movie viewers' expectations, in Austin, B. A. (ed.) 'Current research in film: Audiences, economics, and law', 1. Ablex Publishing, Norwood, NJ, pp. 51-57.

13 O'Brien, J. (1977) 'Experiencing the popular film: An audience gratifications study', unpublished doctoral dissertation, Northwestern University.

14 Eliashberg, J. and Sawhney, M. S. (1994) 'Modeling goes to Hollywood: Predicting individual differences in movie enjoyment', Management Science, Vol. 40, No. 9, pp. 1151-1173.

15 O'Connor P. J. and Sullivan G. L. (1995) 'Market segmentation: A comparison of benefits/attributes desired and brand preference', Psychology \& Marketing, Vol. 12, No. 7, pp. 613-636.

16 Austin, B. A. (ed.) (1985-1991) 'Current research in film: Audiences, economics, and law'. Ablex Publishing, Norwood, NJ.

17 Adams, W. J. and Lubbers, C. A. (2000) 'Promotion of theatrical movies', in Eastman, S. T. (ed.) 'Research in media promotion', Lawrence Erlbaum Associates, Mahwah, NJ.

18 Smith, W. (1956) 'Product differentiation and market segmentation as alternative marketing strategies', Journal of Marketing, Vol. 20, No. 3, pp. 3-8.

19 Haley, R. I. (1995) 'Benefit segmentation: A decision-oriented research tool', Marketing Management, Vol. 4, No. 1, pp. 59-62.

20 O'Connor and Sullivan (1995) op. cit.

21 Wyner (1992) op. cit.
22 Weber, S. (1992) 'Trends in tourism segmentation research', Marketing and Research Today, Vol. 20, No. 2, pp. 116-124.

23 Baloglu, S., Weaver, P. and McCleary, K. W. (1998) 'Overlapping product-benefit segments in the lodging industry: A canonical approach', International Journal of Contemporary Hospitality Management, Vol. 10, No. 4, pp. 159-166.

24 Cermak, D. S., File, K. M. and Prince, R. A. (1994) 'A benefit segmentation of the major donor market', Journal of Business Research, Vol. 29, No. 2, pp. 121-131.

25 Frank, R. E. and Greenberg, M. G. (2000) 'Interest-based segments of TV audiences', Journal of Advertising Research, Vol. 40, No. 6, pp. 55-65.

$26 \mathrm{Kim}$ (2002) op. cit.

27 Rao, V. R. and Winter, F. W. (1978) 'An application of the multivariate probit model to market segmentation and product design', Journal of Marketing Research, Vol. 15, pp. 361-368.

28 Wedel (2001) op. cit.

29 Hutt, E., Brun, R. L. and Mannhardt, T. (2001) 'Simplifying web segmentation', McKinsey Quarterly, No. 3, pp. 12-15.

30 Motion Picture Association of America (2004) 'US Entertainment Industry: 2003 MPAA market statistics', available at www.mpaa.org.

31 McDonald, K. A. (2004) 'TV spots target scattered audiences', Variety, 31st March, p. A6.

32 DeSilva (1998) op. cit.

33 Elberse, A. and Eliashberg, J. (2003) 'Demand and supply dynamics for sequentially released products in international markets: The case of motion pictures', Marketing Science, Vol. 22, No. 3, pp. 329-354.

34 Hayes and Bing (2004) op. cit.

35 Galloway, S. (2003) 'A tangled web', Hollywood Reporter, Vol. 378, 20th May, p. S-1.

36 Kuklenski, V. (2004) 'Believe the HYPE', The Daily News of Los Angeles 3rd June, p. u4, available at http://web.lexisnexis.com/universe/document?_ $\mathrm{m}=332 \mathrm{cb} 68 \mathrm{~b} 523 \mathrm{fe} 3 \mathrm{~b} 0 \mathrm{ad} 651 \mathrm{fo}$ (last accessed 10 October, 2005).

37 Galloway (2003) op. cit.

38 Austin, B. A. (1988) 'Which show to see?' Boxoffice, Oct, pp. 57-66.

39 Geller, M. (1982) 'So what if your movie's "terrific" - Tell me what it's about', Boxoffice, Feb, pp. 22-23, 42.

40 Austin, B. A. (1981) 'Film attendance: Why college students chose to see their most recent film, Journal of Popular Film and Television, Vol. 9, Spring, pp. 43-49.

41 Austin identified seven gratifications or motivations for movie attendance. These gratifications can be described as follows: (1) learning and information (the need to learn about new ideas, new places, new activities, how things work); (2) forget and get away/escape (the need to escape from pressures, responsibilities and problems); (3) enjoyable and pleasant activity (the need to have fun and to be entertained); (4) pass time (the need for something to do, the need to do an activity); (5) relieve loneliness 
(the need to be with others, the need to get relief from a distressing psychological state); (6) behavioural resources (the need to impress others and to be like other people); (7) learning about self (the need for introspective information). Austin, B. A. (1986) 'Motivations for movie attendance', Communication Quarterly, Vol. 34, No. 2, pp. 115-126.

42 Goodale, G. (1998) 'Coming attractions may not be suitable for children', Christian Science Monitor, Vol. 90, No. 133. p. b6.

44 McIntosh, W. D., Murray, J. D., Murray, R. M. and Manian, S. (2003) 'What's so funny about a poke in the eye? The prevalence of violence in comedy films and its relation to social and economic threat in the United States, 1951-2000', Mass Communication \& Society, Vol. 6, No. 4, pp. 345-360.

45 Hayes (2002) op. cit.

46 Advertising expenditures for movies may indicate the belief of movie marketers in the effectiveness of the various media. In 2000, the advertising expenditure for all movies was distributed as follows: network television and spot television: 42.1 per cent; other media (cable television, network radio, spot radio, magazines, outdoor): 18.8 per cent; newspaper: 15.6 per cent; trailers: 6.4 per cent; other non-media costs: 16.3 per cent (MPA Research Dept. 2001, p. 20). The expenditures on trailers as a basis for their effectiveness is a bit misleading because there is little, if any, cost in placing trailers before the public.

47 Graser (2003) op. cit.

48 Movie marketers could also consider producing several trailers with each designed to appeal to a different genre segment.

49 Every fourth person leaving the cinema auditorium was asked to participate.

$50 \mathrm{Kim}$ (2002) op. cit.

51 Baloglu, S., Weaver, P. and McCleary, K. W. (1998)
'Overlapping product-benefit segments in the lodging industry: A canonical approach', International Journal of Contemporary Hospitality Management, Vol. 10, No. 4, pp. 159-166.

52 Participants were asked 'From what you have seen in the preview (trailer) for Lost in Space (for example), to what degree do you expect the movie will excite you?' Other variables responded to were: bore, amuse, embarrass, educate, anger and sadden. Participants were also asked, 'Based on what you saw in the preview (trailer) for Lost in Space (for example), to what degree do you think the movie will make you happy?? Other variables responded to were: carefree, afraid, sexually aroused, enlightened and warm-hearted.

53 Gough, H. G. and Heilbrun, A. B. (1980) 'The adjective checklist manual', Consulting Psychologists Press, Palo Alto, CA; Osgood, C. E., Suci, G. J. and Tannebaum, P. H. (1957) 'The measurement of meaning', University of Illinois Press, Urbanna, IL.

54 Kline, P. (1996) 'An easy guide to factor analysis', Routledge, London.

55 An alpha level of 0.05 was used for all statistical tests.

56 For example, those moviegoers who prefer comedy will attend a movie that contains many instances of slapstick humour. Few, if any, moviegoers prefer a single genre to the exclusion of all other genres. Therefore, a Likert-type scale was used to measure genre preference.

57 DeSilva (1998) op. cit.

58 The structure of the motion picture industry not withstanding. Trailers are not utilised to their full intent, in part because movie studios do not wish to promote a competitor's movie. Movie distributors desire to promote only those films that they distribute, and cinemas do not wish to promote movies that are shown in other cinemas. 